\title{
Upregulation of Acid-Sensing Ion Channel ASIC1a in Spinal Dorsal Horn Neurons Contributes to Inflammatory Pain Hypersensitivity
}

\author{
Bo Duan, ${ }^{1,2 *}$ Long-Jun Wu, ${ }^{1 \star}$ Yao-Qing Yu, ${ }^{3}$ Yu Ding, ${ }^{1}$ Liang Jing,,${ }^{1,4}$ Lin $\mathrm{Xu},{ }^{4}$ Jun Chen, ${ }^{3}$ and Tian-Le Xu ${ }^{1,2}$ \\ ${ }^{1}$ Institute of Neuroscience and State Key Laboratory of Neuroscience, Chinese Academy of Sciences, Shanghai 200031, China, ${ }^{2}$ School of Life Sciences, \\ University of Science and Technology of China, Hefei 230027, China, ${ }^{3}$ Institute for Biomedical Sciences of Pain and Functional Brain Disorders, Tangdu \\ Hospital, Fourth Military Medical University, Xi'an 710038, China, and ${ }^{4}$ Laboratory of Learning and Memory, Kunming Institute of Zoology, Chinese \\ Academy of Sciences, Kunming 650223, China
}

Development of chronic pain involves alterations in peripheral nociceptors as well as elevated neuronal activity in multiple regions of the CNS. Previous pharmacological and behavioral studies suggest that peripheral acid-sensing ion channels (ASICs) contribute to pain sensation, and the expression of ASIC subunits is elevated in the rat spinal dorsal horn (SDH) in an inflammatory pain model. However, the cellular distribution and the functional consequence of increased ASIC subunit expression in the SDH remain unclear. Here, we identify the $\mathrm{Ca}^{2+}$-permeable, homomeric ASIC1a channels as the predominant ASICs in rat SDH neurons and downregulation of ASIC1a by local rat spinal infusion with specific inhibitors or antisense oligonucleotides markedly attenuated complete Freund's adjuvant (CFA)-induced thermal and mechanical hypersensitivity. Moreover, in vivo electrophysiological recording showed that the elevated ASIC1a activity is required for two forms of central sensitization: C-fiber-induced "wind-up" and CFA-induced hypersensitivity of SDH nociceptive neurons. Together, our results reveal that increased ASIC activity in SDH neurons promotes pain by central sensitization. Specific blockade of $\mathrm{Ca}^{2+}$-permeable ASICla channels thus may have antinociceptive effect by reducing or preventing the development of central sensitization induced by inflammation.

Key words: acid-sensing ion channel; spinal dorsal horn; calcium; sensitization; plasticity; inflammation; chronic pain

\section{Introduction}

Inflammation and trauma lead to enhanced pain sensitivity (hyperalgesia), which is in part caused by altered plasticity in the spinal cord (Dubner and Ruda, 1992; Basbaum and Woolf, 1999; Salter, 2005; Hu et al., 2006; Ikeda et al., 2006; Wei et al., 2006). The molecular mechanism underlying this nociceptive plasticity is not fully understood. An important component in inflammation-induced hypersensitivity to thermal and mechanical stimuli (inflammatory pain hypersensitivity) is the amplification of pain-related information resulting from modulation and expression of specific ion channels in the spinal dorsal horn (SDH) (Woolf and Costigan, 1999; Ikeda et al., 2006).

The acid-sensing ion channels (ASICs) belong to the de-

Received March 19, 2007; revised Aug. 20, 2007; accepted Aug. 24, 2007.

This work was supported by National Natural Science Foundation of China Grants 30500116 and 30621062, National Basic Research Program of China Grant 2006CB500800, and Knowledge Innovation Project from the Chinese Academy of Sciences Grant KSCX2-YW-R-35 (T.-L.X.). We thank Drs. Q. Hu, X. Zhang, X.-L. Zhao, Y.-Z. Wang, S.-P. Fan, and Q.-W. Zeng for technical assistance and Dr. M-m. Poo for helpful comments on this manuscript.

*B.D. and L.-J.W. contributed equally to this work.

Correspondence should be addressed to either of the following: Dr. Tian-Le Xu, Institute of Neuroscience, Shanghai Institutes for Biological Sciences, Chinese Academy of Sciences, 320 Yue-yang Road, Shanghai 200031, China, E-mail: tlxu@ion.ac.cn; or Dr. Jun Chen, Institute for Biomedical Sciences of Pain and Functional Brain Disorders, Tangdu Hospital, Fourth Military Medical University, 1 Xinsi Road, Xi'an 710038, China, E-mail: junchen@fmmu.edu.cn.

DOI:10.1523/JNEUROSCI.3364-07.2007

Copyright $\odot 2007$ Society for Neuroscience $\quad 0270-6474 / 07 / 2711139-10 \$ 15.00 / 0$ generin/epithelial $\mathrm{Na}^{+}$channel superfamily. To date, at least six subunits of ASICs have been identified: $1 \mathrm{a}, 1 \mathrm{~b}, 2 \mathrm{a}, 2 \mathrm{~b}, 3$, and 4 (Krishtal, 2003). Their location and properties make ASICs attractive candidates for the sensor of tissue acidosis associated with inflammation, ischemia, and cancer metastases (Wemmie et al., 2006). Indeed, elevation of ASIC subunit expression in the dorsal root ganglion (DRG) was observed during inflammation (Voilley et al., 2001) and could be induced by inflammatory mediators (Voilley et al., 2001; Mamet et al., 2002). Moreover, ASIC inhibitors attenuated peripheral acid-induced hyperalgesia in rats (Dube et al., 2005) and acid-elicited pain in human subjects (Ugawa et al., 2002; Jones et al., 2004), further implicating ASICs in pain sensation. However, previous genetic evidence suggests that deletion of ASIC1 gene increases rather than decreases the sensitivity of the mice to painful stimuli (Mogil et al., 2005; Wemmie et al., 2006). This apparent discrepant result may be attributed to the compensatory expression of different ASIC subunits or other ion channels (Caterina et al., 2000; Bandell et al., 2004). Alternatively, in these complete ASIC1 knock-out mice, nociception may be affected at multiple levels in the CNS.

Peripheral inflammation induces persistent enhancement of nociceptive transmission in the spinal dorsal horn, a process related to central sensitization (Woolf and Costigan, 1999; Woolf and Salter, 2000). Central sensitization is a form of spinal plasticity that shares similar mechanisms with long-term potentiation 
(LTP) of glutamatergic transmission in other brain regions and is generally considered to be a cellular basis of chronic pain (Ji et al., 2003; Salter, 2004). Deletion of ASIC1 gene impairs hippocampal synaptic plasticity and spatial learning in mice (Wemmie et al., 2002), suggesting that ASICs may contribute to central sensitization and nociception. Because peripheral inflammation increases the expression of ASICla subunits in the rat spinal cord (Wu et al., 2004), ASICla may contribute to spinal processing of inflammation-related pain behaviors. To examine this possibility, we investigated the spinal distribution of the ASIC1a subunit and its in vivo functional presence and inflammation-induced changes in its expression in SDH neurons. Behavioral studies and in vivo electrophysiological measurements of nociceptive responses of SDH neurons were also performed to demonstrate that the enhanced ASIC1a channel activity underlies central inflammatory pain sensitization.

\section{Materials and Methods}

Animals. The experimental protocols were approved by the Institutional Animal Care and Use Committee of Institute of Neuroscience, Shanghai, China. All behavioral measurements were done in awake, unrestrained Sprague Dawley rats $(\sim 200 \mathrm{~g})$ of male. Complete Freund's adjuvant (CFA, $50 \%$ in saline, $150 \mu \mathrm{l}$ ) was injected into the plantar surface of the right hindpaw. For intrathecal injection, a polyethylene 10 catheter was implanted at L3-L5 spinal level after rats were anesthetized with sodium pentobarbital $(50 \mathrm{mg} / \mathrm{kg}$, i.p.). In formalin test, a $2.5 \%$ formaldehyde solution $(50 \mu \mathrm{l})$ was injected into the subcutaneous space at the dorsal side of the right hindpaw.

Behavioral test. Animals were assigned in treatment groups in a blinded manner and pain response was measured in a blinded manner. Rats were habituated and basal pain sensitivity was tested before drug administration or surgery. Drugs, antisense oligonucleotide, and vehicle (saline) were administered intrathecally. Psalmotoxin 1 (PcTX1) was obtained as the venom of the South American tarantula Psalmopoeus cambridgei (Escoubas et al., 2000). Thermal paw withdrawal latency was measured using the Hargreaves radiant heat apparatus and averaged over five trials (Wu et al., 2004). Mechanical withdrawal threshold on the plantar surface of the hindpaw was measured with a set of von Frey hairs (North Coast Medical, Morgan Hill, CA) in the range of 0.4-26 gm (0.4, $1.2,2,4,6,8,10,15,26 \mathrm{gm})$. A modification (the value of cutoff is $26 \mathrm{gm}$ ) of the "up-down" method was used to determine the value at which paw withdrawal occurred $50 \%$ of the time (Chaplan et al., 1994), interpreted to be the mechanical nociceptive threshold. The formalin-induced typical flinching behavior of the injected paw was counted at 2 min intervals for $60 \mathrm{~min}$, starting immediately after formalin injection. At $0 \mathrm{~min}$ and 28 min, saline or PcTX1 was injected into the SDH intrathecally.

Acute isolation of SDH neuron. Dorsal horn neurons were mechanically dissociated from the rat according to the previous study by $\mathrm{Wu}$ et al. (2004). In brief, 2-week-old Sprague Dawley rats were killed by decapitation and a segment of lumbosacral (L4-S2) spinal cord was dissected out. Then, $400 \mu \mathrm{M}$ transverse slices were sectioned with a vibratome tissue slicer (VT1000S; Leica, Wetzlar, Germany) in the incubation solution. A vibration-isolation system was used to mechanically dissociate SDH neurons from the spinal slices.

Spinal neuron culture. The SDH neurons from 15-d-old embryonic Sprague Dawley rats were isolated by a standard enzyme treatment protocol (Jiang et al., 2006). Briefly, SDH neurons were dissociated in $\mathrm{Ca}^{2+}$. free saline with sucrose $(20 \mathrm{~mm})$ and plated $\left(1 \times 10^{5} \mathrm{cell} / \mathrm{ml}\right)$ on poly-Dlysine (Sigma, St. Louis, MO)-coated cover glasses. The neurons were grown in DMEM (Invitrogen, Eugene, OR) with L-glutamine plus 10\% fetal bovine serum (Invitrogen) and 10\% F12 nutrient mixtures (Invitrogen). Neurobasal medium ( $2 \mathrm{ml}$; Invitrogen) with $2 \%$ B27 serum-free supplements (Invitrogen) was replaced $1 \mathrm{~d}$ after cell plating. The cultures were maintained at $37^{\circ} \mathrm{C}$ in a $5 \% \mathrm{CO}_{2}$ humidified atmosphere.

SiRNA transfection. After synthesizing four chemically modified oligonucleotides (5' CUG AGC GUG UGC AGU ACU Adtdt 3'; 5' GAU GAA UAU UUG CCU GUG Udtdt $3^{\prime}$; $5^{\prime}$ CUC AAU GAG UUC CGC UUU
Adtdt 3'; 5' UUC GAC UCC UAC AGC AUC Adtdt 3'), we assessed the efficiency and specificity of siRNA oligos of ASICla with Western blotting and selected two sequences (5' CUG AGC GUG UGC AGU ACU Adtdt 3', named siRNA1; 5' CUC AAU GAG UUC CGC UUU Adtdt 3', named siRNA2) for additional experiments. A scrambled RNA (5' UUC UCC GAA CGU GUC ACG Udtdt $3^{\prime}$ ) was used as control RNA. For siRNA electroporation (Gao et al., 2005), we used the rat Neuron Nucleofector kit (Amaxa, Koeln, Germany) according to the manufacturer's instructions. Transfected neurons were used for experiments $4 \mathrm{~d}$ after siRNA transfection.

Antisense delivery. The 18-mer antisense oligonucleotide (AS) was designed in the $5^{\prime}$ part of the coding sequence (5' GTG CCC GCT TCA GAG ACA $\left.3^{\prime}\right)$, and the inverted sequence (IS) was used as a control ( $5^{\prime}$ ACA GAG ACT TCG CCC GTG 3') (Ettaiche et al., 2006). Transfection of cultured SDH neurons with AS or IS was done with oligofectamine reagent (Invitrogen) using the protocol of the supplier, scaling up the given proportions for $35 \mathrm{~mm}$ dishes to keep $2.7 \mathrm{ng} / \mu$ l oligonucleotide final concentration. Intrathecal treatment with both AS and IS was used at $45 \mu \mathrm{g}$ in $10 \mu \mathrm{l}$ of saline per rat, twice daily for $4 \mathrm{~d}$. Intrathecal treatment with $10 \mu \mathrm{l}$ of saline was used as vehicle control. In CFA groups, CFA was injected into the right hindpaw of rats on the third day of the $4 \mathrm{~d}$ antisense administration period. Rats of post-treatment groups were used after $4 \mathrm{~d}$ of cessation of antisense injection.

Transfection of $\mathrm{CHO}$ cell. All constructs were expressed in Chinese hamster ovary $(\mathrm{CHO})$ cells. Transient transfection of $\mathrm{CHO}$ cells was performed as reported previously (Wu et al., 2004; Wang et al., 2006). Cotransfection with a green fluorescent protein (GFP) expression vector, pEGFP-N1, was used to enable identification of transfected cells for patch clamping by monitoring GFP fluorescence in some experiments. When two ASIC subunits were expressed, the plasmids were cotransfected in a ratio of 1:1. Electrophysiological recordings were performed $16-48 \mathrm{~h}$ after transfection.

Whole-cell recordings. Experiments were conducted with the Molecular Devices (Foster City, CA) system (Axoclamp 200B, Digidata 1320A, pClamp 9). Voltage-clamp experiments were performed as described previously (Wu et al., 2004). Patch pipettes $(4-6 \mathrm{M} \Omega$ ) were filled with the following (in mM): $120 \mathrm{KCl}, 30 \mathrm{NaCl}, 0.5 \mathrm{CaCl}_{2}, 1 \mathrm{MgCl}_{2}, 5 \mathrm{EGTA}, 2$ MgATP, and 10 HEPES, pH 7.2. The standard extracellular solution contained (in mM) $150 \mathrm{NaCl}, 5 \mathrm{KCl}, 1 \mathrm{MgCl}_{2}, 2 \mathrm{CaCl}_{2}$, and 10 glucose, buffered to various $\mathrm{pH}$ values with either $10 \mathrm{~mm}$ HEPES, pH 6.0-7.4, or $10 \mathrm{~mm}$ 2-( $N$-morpholino)-ethanesulfonic acid (MES), $\mathrm{pH}<6.0$. All drugs for electrophysiological experiments were purchased from Sigma except for PcTX1.

$\mathrm{Ca}^{2+}$ imaging. Intracellular $\mathrm{Ca}^{2+}$ imaging was performed as previously described (Gao et al., 2005; Wang et al., 2006). Primary cultured $\mathrm{SDH}$ neurons at $4 \mathrm{~d}$ in vitro (DIV) were incubated with $1 \mu \mathrm{M}$ Fura-2acetoxymethyl ester for $20 \mathrm{~min}$ at $37^{\circ} \mathrm{C}$, washed three times, and incubated in standard extracellular solution for $30 \mathrm{~min}$. Experiments were performed by using a $40 \times$ UV fluor oil-immersion objective lens, and the fluorescence-ratio images were acquired by using alternating excitation wavelengths $(340 / 380 \mathrm{~nm}$ ) with a monochromator (Polychrome IV; Till, Munich, Germany). Fura-2 fluorescence was detected at emission wavelength of $510 \mathrm{~nm}$. Digitized images were acquired and analyzed in a personal computer controlled by SimplePCI (Compix, Sewickley, PA). Ratio images $(340 / 380 \mathrm{~nm})$ were further analyzed by Origin 7.0.

Immunohistochemistry and Western blotting. Adult male Sprague Dawley rats ( $\sim 200 \mathrm{~g})$ were anesthetized with sodium pentobarbital $(50 \mathrm{mg} /$ $\mathrm{kg}$, i.p.) and perfused with $4 \%$ paraformaldehyde in phosphate buffer $(0.1 \mathrm{M}, \mathrm{pH} 7.4)$. The spinal cord was removed and cryoprotected overnight in a $30 \%$ sucrose solution at $4^{\circ} \mathrm{C}$. Transverse frozen sections $(30$ $\mu \mathrm{m}$ thick) were cut from the lumbar cord (L4-L5). Coimmunostaining was performed on parallel sections with antibodies against ASICla (1: 200; Millipore, Temecula, CA), NeuN (1:200; Millipore), calcitonin gene-related peptide (CGRP; 1:500; Santa Cruz Biotechnology, Santa Cruz, CA), GFAP (1:50; Millipore), oligodendrocyte antibody [receptorinteracting protein (RIP); 1:5000; Millipore], or OX-42 (CD11b, microglial marker; 200; BD Biosciences, San Jose, CA). Secondary antibodies included goat anti-rabbit FITC and anti-mouse Rhodamine (1:70; Rockland, Gilbertsville, PA). Fluorescein-labeled Griffonia simplicifolia lectin 
isolectin B4 (IB4; 1:100; Vector Laboratories, Burlingame, CA) was directly used for IB4 staining. In the Western blotting experiments, protein samples from cultured SDH neurons (see Fig. 1 B, DIV 4; supplemental Fig. 2, DIV 13, available at www.jneurosci.org as supplemental material) or SDH homogenates (see Figs. 3, 4) were separated by SDS-PAGE gel and transferred to polyvinylidene difluoride filters. The filters were incubated overnight at $4^{\circ} \mathrm{C}$ with anti-ASIC1a, anti-ASIC2a (1:200; Alomone Labs Jerusalem, Israel), or anti-GAPDH (1:1000; KangChen, Shanghai, China) antibodies and finally visualized in ECL solution and exposed onto X-films for 1-10 min. Image-Pro Plus 6.0 (Media Cybernetics, Bethesda, MD) was used for the analysis of optic density of ASICla in SDH neurons at the neuronal level. In brief, we first costained spinal cord section with antibodies against ASICla and NeuN. Then, we extracted the shape information of neurons from NeuN-positive staining and merged the ASICla staining with the extracted shape information of the neuron and quantified the fluorescence intensity of ASICla staining in each neuron in the SDH.

In vivo single-unit recordings. Recordings were performed as reported previously (Chen et al., 1998). In brief, the adult male Sprague Dawley rat $(\sim 200 \mathrm{~g})$ was initially anesthetized with sodium pentobarbital $(50 \mathrm{mg} /$ $\mathrm{kg}$, i.p.) and maintained by tracheal intubation $(1.1 \% ; 2-2.5 \mathrm{cc}$ tidal volume; $60-70$ strokes per minute). A laminectomy was performed from T13-L1 vertebrae to expose the lumbar enlargement for spinal "wide dynamic range" (WDR) neuron recording. A paraffin pool was made with ambient skin flaps around the exposed incision area and filled with warm paraffin oil $\left(37^{\circ} \mathrm{C}\right)$ to prevent drying of the exposed tissue. Core body temperature was monitored through a thermistor probe inserted into the rectum and maintained at $37.5 \pm 0.5^{\circ} \mathrm{C}$ by means of a feedbackcontrolled heating pad under the ventral surface of the abdomen. Extracellular single-unit recordings were made from L4-L5 with glass capillary microelectrodes $(10-15 \mathrm{M} \Omega$, filled with $0.5 \mathrm{~m}$ sodium acetate). Explorations with microelectrodes were made in the dorsal horn using an electronically controlled microstepping manipulator in $2 \mu \mathrm{m}$ steps. Electrical current pulse (electric stimulator isolator, SEN-3301; isolator, SS202J; Nihon Kohden, Tokyo, Japan) at a consistent strength (100 $\mu \mathrm{A}, 50$ $\mu \mathrm{s}, 1 \mathrm{~Hz}$ ) was applied to the skin of the hindpaw ipsilateral to the recording site as a search stimulus to find WDR neurons. After successful identification of a single WDR unit (Chen et al., 1998), the unit responsiveness to $10 \mathrm{~s}$ mechanical stimuli was recorded. The mechanical stimuli were (1) brush, performed by stroking on the center of the cutaneous receptive field ( $\mathrm{cRF}$ ) at a frequency of twice per second with a hairy paint brush; (2) pressure, performed by picking up a fold of skin with flattened alligator clip to produce a consistent strength that was not painful when tested on the skin; and (3) noxious pinch, performed by pinching a fold of skin with a small serrated clip to produce a consistent strength, which was obviously painful when tested on the experimenter's skin. The force of pressure and pinch stimuli applied to the cRF was uniform although the precise strength of the stimulus was not available. Only WDR neurons without background discharges were studied further. To evoke "wind-up," 16 suprathreshold stimuli (at 1.5-fold of the threshold), with a $2 \mathrm{~ms}$ pulse width at $0.5 \mathrm{~Hz}$, were applied to each WDR neuron. Threshold was taken as the current required to consistently evoke one or more spikes to one electrical current pulse. Control trials were performed at 10 min intervals and drug or saline was applied directly to the dorsal surface of the spinal cord in a volume of $10 \mu \mathrm{l}$ after three stable control trials. To evaluate the effects of PcTX1 on wind-up and mechanical stimulation, the time point was measured at $15 \mathrm{~min}$ after the drug treatment. The original signals were filtered $(20 \mathrm{~Hz}$ to $20 \mathrm{kHz}$ ) by an alternating current/ direct current differential amplifier (A-M Systems, Sequim, WA) and simultaneously sampled with PowerLab/8SP (AD Instruments, Castle Hill, Australia) at $10 \mathrm{kHz}$. Chart 4.0 software (AD Instruments) was applied for recording and off-line analysis.

Data analysis. Results were expressed as the mean \pm SE. Statistical comparisons were performed using unpaired or paired Student's $t$ tests or one-way ANOVA where significance was indicated by two-tailed $p$ values $\leq 0.05$.

\section{Results \\ $\mathrm{Ca}^{2+}$-permeable ASIC1a channels are the major ASIC in SDH neurons}

To understand the presence of ASICla-containing channels in SDH neurons, we examined the contribution of ASIC1a homomeric channels to acid-induced currents in these cells. We first tested the effect of PcTX1, a specific antagonist of homomeric ASIC1a channels. Consistent with a previous report (Escoubas et al., 2000), we found that in CHO cells heterologously expressing ASIC1a, 1b, and 2a, either alone or together, PcTX1 only blocked homomeric ASICla channel-mediated currents, without affecting homomeric ASIC2a channel- or heteromeric ASIC1a $+2 \mathrm{a}-$ mediated currents (supplemental Fig. 1, available at www. jneurosci.org as supplemental material). Interestingly, the same concentration of PcTX1 markedly enhanced the peak amplitude of ASIC1b channel-mediated currents (supplemental Fig. 1, available at www.jneurosci.org as supplemental material) and prolonged the channel desensitization $(\tau=1.4 \pm 0.1 \mathrm{~s}$ in control currents vs $\tau=3.9 \pm 0.5 \mathrm{~s}$ in PcTX1-treated currents, $n=6$ ), consistent with a previous report that PcTX1 promotes ASIC1b channel opening (Chen et al., 2006). In contrast, heat-inactivated (boiled) PcTX1 was ineffective in either reducing ASIC1a or enhancing ASIC1b channels (data not shown). Similar to its inhibition on recombinant ASIC1a channels in acutely dissociated SDH neurons, we found that PcTX1 $(5 \mu \mathrm{g} / \mathrm{ml})$ reduced the peak amplitude of acid-induced current to $14.1 \pm 1.1 \%(n=8)$ of the control, without affecting the currents elicited by NMDA, kainate, or GABA (Fig. $1 A$ ).

Additional experiments were performed to examine the effect of suppressing ASIC1a expression in cultured SDH neurons by RNA interference. Although we noted an apparent inconsistency of peak amplitude of acid-induced currents between acutely dissociated and cultured SDH neurons $(804 \pm 105 \mathrm{pA}$ in acutely isolated neurons, $n=8$, vs $458 \pm 77 \mathrm{pA}$ in cultured neurons, $n=$ $15 ; p<0.05$ ) (Fig. $1 A, C$ ), the ASIC subunits were identical in the two groups, as reflected by RT-PCR and Western blotting measurements (data not shown). Out of four double-stranded siRNA sequences prepared against ASIC1a (see Materials and Methods), we found that two sequences were effective in reducing ASICla expression in cultured SDH neurons $4 \mathrm{~d}$ after transfection. The ASIC1a expression was reduced to $45.4 \pm 4.5 \%$ (siRNA1) or $28.5 \pm 14.1 \%$ (siRNA2) of that in cells transfected with the control RNA of a scrambled sequence (Fig. $1 B$, control). The expression of ASIC2a was not affected. Whole-cell recordings in neurons $4 \mathrm{~d}$ after transfection showed that ASIC1a silencing resulted in a marked reduction of the acid-induced current (at $\mathrm{pH}$ 6.0) from $47.3 \pm 7.7 \mathrm{pA} / \mathrm{pF}$ (control RNA) to $20.6 \pm 4.1 \mathrm{pA} / \mathrm{pF}$ (siRNA1) or $14.2 \pm 1.9 \mathrm{pA} / \mathrm{pF}$ (siRNA2) (Fig. 1C). In these recordings, we found no evidence of ASIC2a-containing channels, which normally exhibit a transient component followed by a plateau phase after application of acidic solutions (Wu et al., 2004). Together, these results indicate that ASICla subunit is the major functional subunit underlying ASIC currents in SDH neurons.

Homomeric ASICla channels are permeable to $\mathrm{Ca}^{2+}$ (Xiong et al., 2004; Yermolaieva et al., 2004; Gao et al., 2005; Zha et al., 2006). Using Fura-2 fluorescence ratio imaging of $\mathrm{Ca}^{2+}$, we observed an elevation of intracellular $\mathrm{Ca}^{2+}$ concentration $\left(\left[\mathrm{Ca}^{2+}\right]_{\mathrm{i}}\right)$ in response to acidic solution ( $\mathrm{pH}$ 5.0) in cultured $\mathrm{SDH}$ neurons (Fig. $1 D_{1}$, top). This acid-induced $\mathrm{Ca}^{2+}$ elevation was reversibly blocked by $100 \mu \mathrm{M}$ amiloride, a nonspecific ASIC antagonist (Fig. $1 D_{1}$, second panel). Downregulating ASICla expression with ASIC1a-specific siRNA significantly reduced the acid-induced 
$\mathrm{Ca}^{2+}$ elevation without affecting NMDA receptor-mediated $\mathrm{Ca}^{2+}$ elevation (Fig. $1 D_{1}$, bottom two panels, $\left.D_{2}\right)$. This $\mathrm{Ca}^{2+}$ elevation may be attributed to $\mathrm{Ca}^{2+}$ influx through homomeric ASIC1a channels or other $\mathrm{Ca}^{2+}$ channels as a result of ASICmediated depolarization. We found that acid-induced $\mathrm{Ca}^{2+}$ elevation was indeed markedly reduced after the pharmacological blockade of voltage-gated $\mathrm{Na}^{+}$and $\mathrm{Ca}^{2+}$ channels as well as glutamate receptors by a mixture of inhibitors including TTX, $\mathrm{CdCl}_{2}, \mathrm{D}-\mathrm{APV}$, and CNQX (Fig. $1 D_{2}$, referred to as “TCAC"). However, a residual $\mathrm{Ca}^{2+}$ elevation remained even with the TCAC treatment, consistent with the presence of $\mathrm{Ca}^{2+}$-permeable homomeric ASIC1a channels and the notion that these channels contribute to $\mathrm{Ca}^{2+}$ signaling in SDH neurons. Silencing ASICla by siRNA resulted in a significantly further reduction of the residual $\mathrm{Ca}^{2+}$ signal (Fig. $\left.1 D_{2}\right)$.

\section{Blockade of spinal ASIC1a channel activity reduces nociceptive behaviors in inflamed rats}

To address the role of $\mathrm{Ca}^{2+}$-permeable ASIC1a channels of SDH neurons in nociception, we tested the effect of local blockade of homomeric ASICla channels with PcTX1 on thermal and mechanical hypersensitivity induced by subcutaneous injection of CFA into one of the rat hindpaws (Stein et al., 1988). The paw withdrawal latency (PWL) and the paw withdrawal threshold (PWT) in response to heat or mechanical stimulation were significantly decreased $1 \mathrm{~d}$ after CFA injection and the effect persisted for at least $3 \mathrm{~d}$ in CFAtreated rats, compared with that in control rats injected with saline (Fig. $2 A, C$ ). Intrathecal injection of PcTX1 (10 $\mu \mathrm{l}, 0.5$ $\mathrm{mg} / \mathrm{ml}$ total protein, $\sim 25 \mu \mathrm{g} / \mathrm{kg}$ ) $1 \mathrm{~d}$ after CFA injection significantly attenuated both thermal and mechanical hypersensitivity induced by the CFA treatment. This antihyperalgesic effect began 5 min after PcTX1 injection and decayed over the subsequent 20 min (Fig. $2 B, D$ ). The effect of PcTX1 was estimated by the percentage reduction of PWL, which showed a clear dose dependence (Fig. $2 E$ ). Intrathecal injection of amiloride $(10 \mu \mathrm{l}, 53.2$ $\mu \mathrm{g} / \mathrm{ml}, \sim 0.5 \mu \mathrm{g} / \mathrm{kg}$ ), the nonspecific ASIC antagonist, also reversed CFA-induced thermal hypersensitivity with a similar time course (Fig. 2 F). These effects of intrathecal PcTX1 and amiloride injections were not caused by drug-induced changes in locomotor functions, because placing, grasping, and righting reflexes of the injected rats were normal (supplemental Table 1, available at www.jneurosci.org as supplemental material). In addition, boiled PcTX1 was not antinociceptive when it was intrathecally injected ( $n=3$ rats) (data not shown).

To investigate whether ASIC1a subunit in the SDH plays an essential role in inflammatory pain hypersensitivity, we further performed antisense knockdown experiments. In cultured SDH neurons $10 \mathrm{~d}$ in vitro, treatment of the cells with an AS against
ASIC1a (Ettaiche et al., 2006) for 3 d significantly decreased the expression of ASIC1a to $31.5 \pm 7.3 \%$ of the control, which was transfected with an oligonucleotide coding IS of the antisense (supplemental Fig. 2, available at www.jneurosci.org as supplemental material). We then tested the effect of the two oligonucleotides in normal or inflamed rats. As indicated in Figure $3 A$, intrathecal injection of ASIC1a AS twice a day for $4 \mathrm{~d}$ reduced CFA-induced ASIC1a expression in the SDH homogenate (see Materials and Methods) to $54.4 \pm 7.2 \%$ of the saline control. In contrast, IS treatment did not influence the ASICla expression ( $104.0 \pm 4.1 \%$ of the saline control). In parallel experiments, we found that intrathecal administration of ASIC1a AS significantly reduced the thermal and mechanical hypersensitivity in the CFAinflamed rats, as indicated by higher values of PWL and PWT (Fig. 3B). Four days after cessation of antisense injections (posttreatment group), both the expression level of ASIC1a (Fig. 3A, top right) and the pain hypersensitivity (Fig. $3 B$ ) showed no significant difference between the AS and saline or IS control groups.

In contrast to that observed in inflamed rats, intrathecal injec- 
A

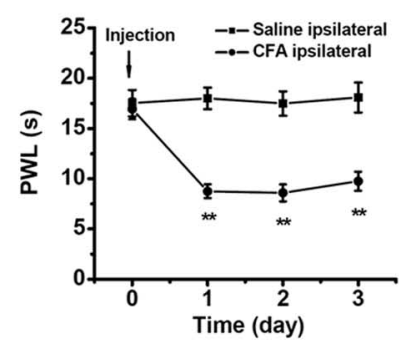

C

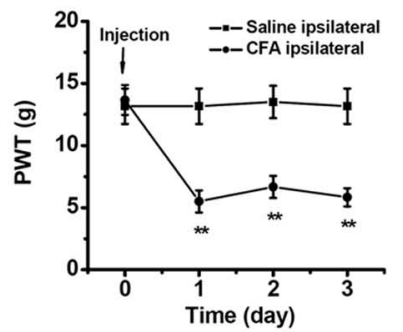

E

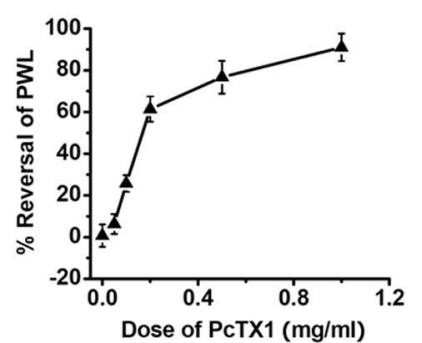

B

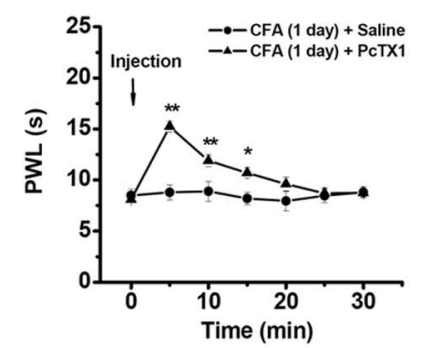

D

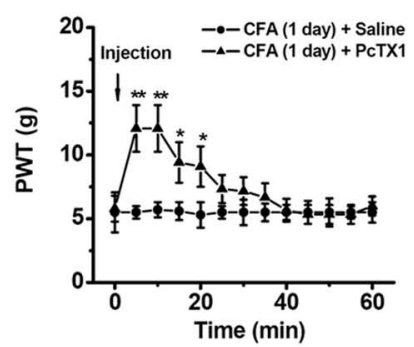

$\mathbf{F}$

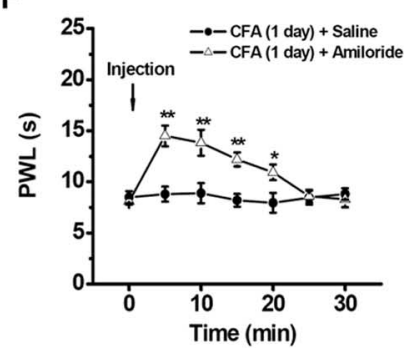

A
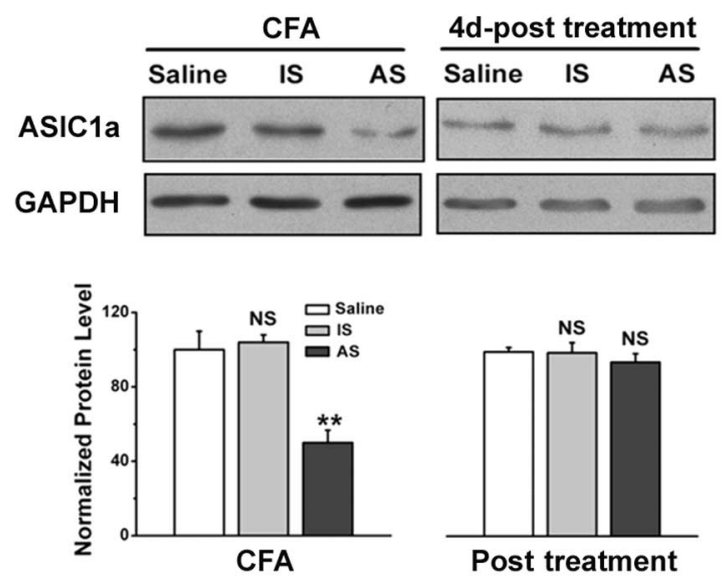

B
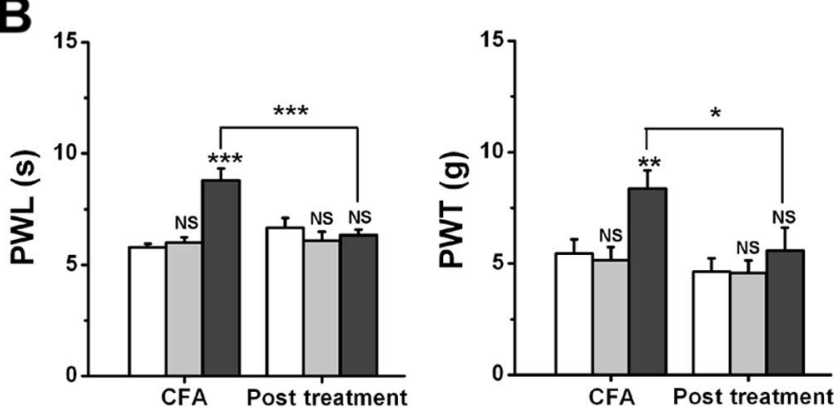

Figure 3. Intrathecal injection of ASIC1a antisense oligonucleotide suppressed pain response of inflamed rats. $A$, Western blot analysis indicated that delivery of a specific ASIC1a AS significantly reduced the expression of ASIC1a in the SDH compared with saline control groups in CFA-treated rats. In contrast, treatment with IS did not affect ASIC1a expression. After $4 \mathrm{~d}$ of cessation of AS or IS injection (4d-post treatment), the expression of ASIC1a was comparable with saline control. The relative levels of ASIC1a protein expression were quantified by densitometry. Each group of data (mean $\pm \mathrm{SE}$ ) was from three independent rats and was normalized by the mean value for those from three rats in corresponding saline group. ${ }^{* *} p \leq 0.01 \mathrm{com}-$ pared with each saline control; NS, No significant difference (Student's unpaired $t$ test). $\boldsymbol{B}$, Behavioral changes parallel the ASIC1a protein reduction. Data represent the mean \pm SE (AS group of CFA rats, $n=12$; saline group of CFA rats, $n=12$; antisense group of post-treatment rats, $n=11$; saline group of post-treatment rats, $n=7$ ). The bracket indicates significant difference from corresponding points. ${ }^{*} p \leq 0.05 ;{ }^{* * *} p \leq 0.001$ (Student's unpaired $t$ test). The white, light gray, and dark gray columns in $B$ represent saline, IS, and AS, respectively, as shown in $A$.

protein, $\sim 25 \mu \mathrm{g} / \mathrm{kg}$ ) immediately after formalin administration had no effect on the early phase of the formalin response, but the same PcTX1 injection reduced the second phase of formalininduced pain behavior (Fig. 5A). This result indicates spinal sensitization caused by the activation of ASIC1a channel.

To address whether peripheral ASICs also play a role in CFAinduced pain hypersensitivity, we injected PcTX1 (10 $\mu \mathrm{l}, 0.5$ $\mathrm{mg} / \mathrm{ml}$ total protein, $\sim 25 \mu \mathrm{g} / \mathrm{kg}$ ) subcutaneously into the hindpaw treated with CFA. Neither the normal baseline PWL (Fig. 5B, top two groups) nor the CFA-induced reduction in PWL (Fig. 5B, bottom two groups) was affected. Thus, ASICla channels appear to play a major role in central but not peripheral nociception, consistent with the previous observation that ASIC subunits other than ASICla may be involved in transducing nociceptive signals at the periphery (Sluka et al., 2003).

Localization of ASIC1a in SDH neurons, but not central DRG nerve terminals

The above studies showed that behavioral response to nociceptive stimuli in naive rats was not affected by intrathecal injection flects a combination of ongoing sensory input and central sensitization. Intrathecal injection of PcTX1 $(10 \mu \mathrm{l}, 0.5 \mathrm{mg} / \mathrm{ml}$ total 
of PcTX1 and ASIC1a antisense oligonucleotide (Fig. 4). This suggests that ASIC1a channels in SDH neurons are not involved in physiological nociception. To determine how spinal ASICla channels may function in inflammatory pain, we examined the cellular distribution of ASIC1a in the SDH after peripheral CFA injection using the immunostaining method. The majority of SDH cells exhibiting ASICla staining were found to contain NeuN, a specific neuronal marker (Mullen et al., 1992), indicating that ASICla was mainly expressed in neurons (Fig. 6D, top). Moreover, an increased neuronal ASICla staining was observed in superficial layers of SDH ipsilateral to the inflammatory side, compared with that of contralateral $\mathrm{SDH}$ or the SDH of sham-operated rats without CFA injection (Fig. $6 A-C$ ). To test whether ASIC1a is expressed in the central terminal of DRG neurons, we costained ASIC1a with CGRP, a neuropeptide contained in the nerve terminals of a subpopulation of DRG neurons (Hokfelt et al., 1992). We found that the distribution of ASIC1a and CGRP was mostly nonoverlapping (Fig. 6D, bottom). Furthermore, ASICla did not colocalize with $\mathrm{IB}_{4}$ (supplemental Fig. 3, available at www.jneurosci.org as supplemental material), a marker for nonpeptidergic small DRG neurons (Silverman and Kruger, 1990), consistent with the report that the IB4-positive DRG neurons express ASIC1a at a very low level (Poirot et al., 2006). In agreement with the previous report that ASICs were absent at central DRG terminals (GarciaAnoveros et al., 2001), our result indicated that the elevated expression of ASICla was restricted to SDH neurons rather than the central terminals of DRG neurons, consistent with our behavioral finding of central, but not peripheral involvement of ASICs (Fig. $5 A, B)$. Furthermore, ASICla was not colocalized with the astrocyte marker GFAP, the oligodendrocyte marker RIP, or the microglia marker OX-42 (supplemental Fig. 4, available at www. jneurosci.org as supplemental material). Thus, we concluded that peripheral inflammation selectively increased the expression of ASIC1a in SDH neurons. Because the expression of ASIC1a is also upregulated in DRG after peripheral inflammation (Voilley et al., 2001), our finding suggests that ASIC upregulation in DRG serves other functions in the DRG cell body or peripheral terminals.

Enhanced ASIC1a activity contributes to central sensitization To address the relevance of ASIC1a in the development of inflammatory pain hypersensitivity, we next investigated the mechanism by which ASICla channels participate in nociceptive processing in SDH neurons. Two phenomena are known to reflect central sensitization underlying inflammatory pain: C-fiber stimulation-induced wind-up, a progressive increase in spike discharges, and CFA-induced hypersensitivity of SDH nociceptive neurons (Woolf and Salter, 2000; Salter, 2004). In vivo single-unit recordings were made from WDR SDH neurons, which are responsible for nociceptive transmission and spinal flexion reflex (Jiang et al., 1995). We found that the wind-up of single-unit activity evoked by prolonged repetitive C-fiber stimulation $(0.5$
B

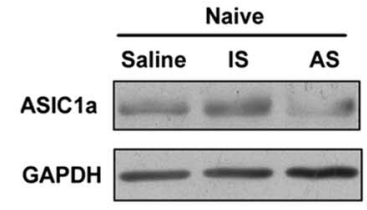

C
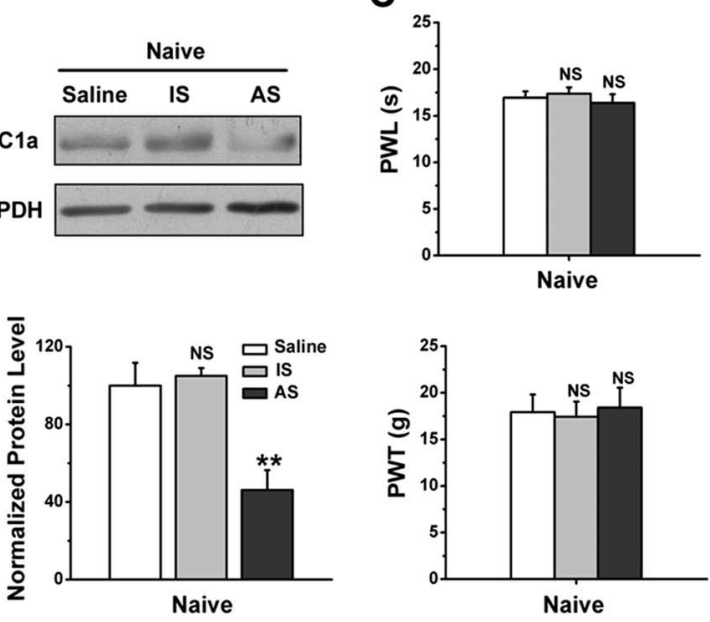

Figure 4. Central ASIC1a did not affect physiological nociceptive behavior. $\boldsymbol{A}$, Blockade of ASIC1a did not affect normal thermal ermal and mechanical nociceptive transmission. Data are shown as mean + SE ( $n=6$ for ot influence ASIC1 1 expression. Each group of data (mean + SE) was from three independent rats and was normalized by the unpaired $t$ test). $C$ Neither injection of AS of ASIC1 a nor IS of ASIC1 altered normal thermal and mechanical nociceptive transmission ( $n=11$ in AS group; $n=9$ in IS group; $n=11$ in saline group, Student's unpaired $t$ test). The white, light gray, and dark gray columns in $\boldsymbol{C}$ represent saline, IS, and AS, respectively, as shown in $\boldsymbol{B}$.

$\mathrm{Hz}, 2 \mathrm{~ms}, 16$ pulses), which mimics persistent C-fiber activation during inflammation, was mostly attenuated by infusion with PcTX1 (10 $\mu \mathrm{l}, 0.5 \mathrm{mg} / \mathrm{ml}$ total protein, $\sim 25 \mu \mathrm{g} / \mathrm{kg}$ ), whereas the same infusion with saline had no effect ( $n=6$ neurons in 6 rats) (Fig. $7 A, B$ ). Because the wind-up reflects activity-dependent synaptic integration in the spinal cord (Herrero et al., 2000; Woolf and Salter, 2000), these findings suggest that ASIC1a channels contribute to spinal neuron sensitization underlying inflammatory pain hypersensitivity.

The ASICla channels appeared to play a specific role in inflammation-induced nociception, because PcTX1 infusion of naive rats had no effect on WDR neuronal activity in response to non-noxious (brushing) and noxious (pressing and pinching) mechanical stimuli applied to peripheral receptive fields (Fig. $7 C, D)$. This is consistent with the observed behavioral response to nociceptive stimuli in naive rats (Fig. 4). In contrast, in rats with CFA-induced inflammation, PcTX1 significantly attenuated the hyperactivity of WDR neurons in response to noxious mechanical stimuli, whereas the brush-evoked hyperactivity of WDR neurons was not significantly affected ( $p=0.384$; PostPcTX1 vs Pre-PcTX1: $59.6 \pm 18.6$ vs $83.0 \pm 17.3$, in brushing-test group) (Fig. $7 C, D$ ). These results indicate that ASIC1a channels are not involved in normal sensory transmission in the spinal cord, but participate specifically in inflammatory pain hypersensitivity.

\section{Discussion}

In the present study, we demonstrated that ASIC1a channels in SDH neurons are essential for inflammation-induced pain hypersensitivity and spinal neuron sensitization. This conclusion is based on three lines of evidence. First, SDH neurons express a high density of $\mathrm{Ca}^{2+}$-permeable homomeric ASICla channels. Second, both genetic suppression and pharmacological blockade of homomeric ASIC1a channels attenuate inflammatory pain be- 


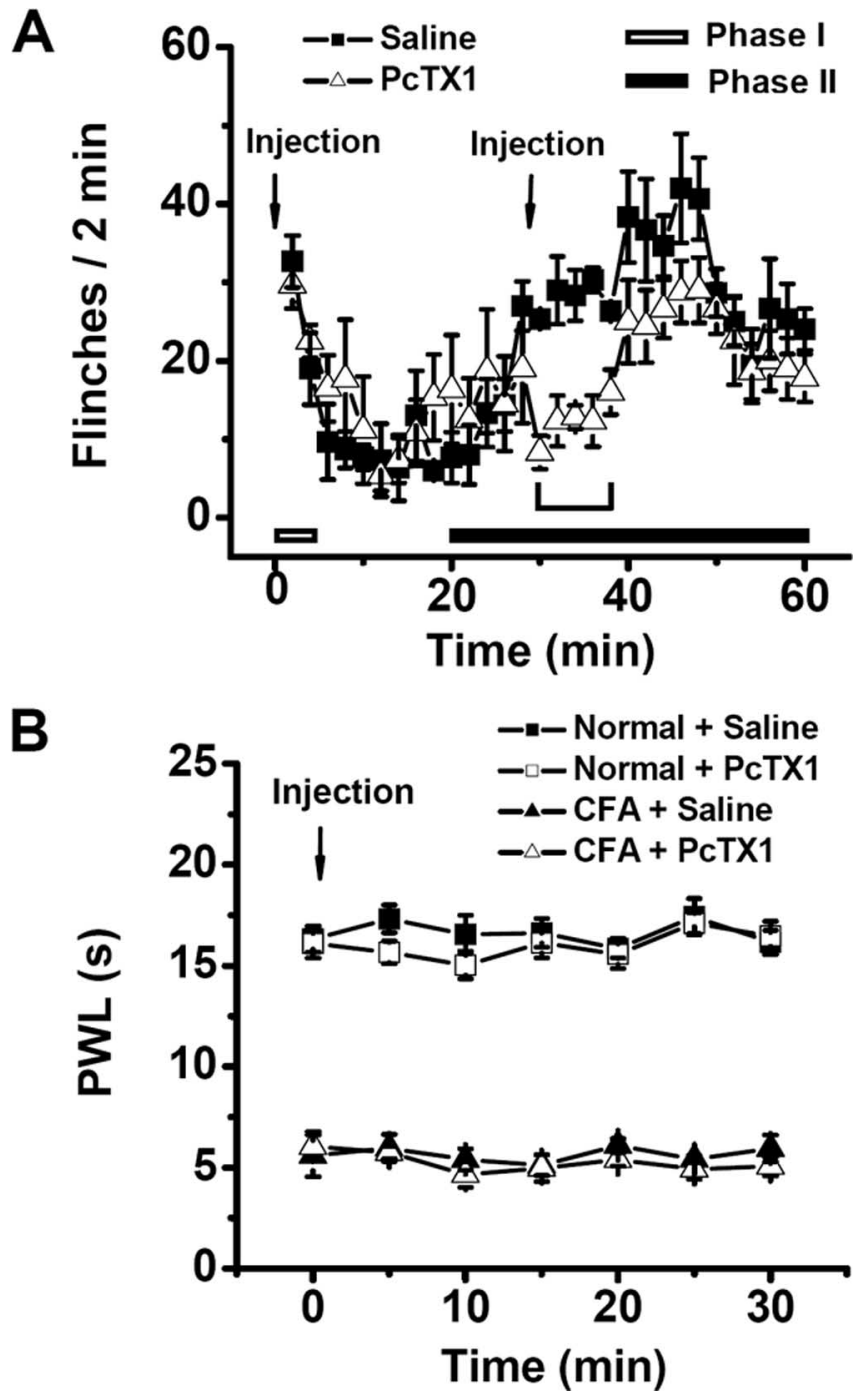

Figure 5. Central but not peripheral ASIC1a contributed to nociceptive transmission. $\boldsymbol{A}$, Intrathecal injection of PcTX1 inhibited the late phase (phase 2) of flinch in the formalin test, but had no detectable effect in the early phase (phase 1). Data are shown as mean \pm SE $(n=6$ for each group). The bracket indicates significant difference from corresponding points in the saline group ( $p<0.05$, Student's unpaired $t$ test). $\boldsymbol{B}$, Intraplantar PcTX1 injection had no effect on CFA-induced reduction of PWL or on PWL of rats injected with saline instead of (FA (normal). Data are shown as mean $\pm \mathrm{SE}$ ( $n=6$ for each group) compared with the corresponding intraplantar saline-treated group (one-way ANOVA test, $p>0.05$ for normal and (FA groups).

haviors of rats. Third, peripheral inflammation upregulates the expression of ASICla protein in SDH neurons and preventing homomeric ASIC1a channel activity in the spinal cord reduces central sensitization, as reflected by the wind-up of SDH neuronal activity induced by $\mathrm{C}$-fiber stimulation and the elevated firing of SDH neurons induced by peripheral inflammation. Spinal cord also expresses detectable levels of ASIC2a and 2b (Wu et al., 2004). Although changes in other types of ASICs may be induced by antisense suppression of ASICla expression, data from the acute blockade of ASIC1a channels with specific inhibitor PcTX1 establishes ASIC1a as a major contributor to inflammatory pain hypersensitivity.

\section{ASIC1a channels contribute specifically to pain} hypersensitivity and spinal sensitization We found that local blockade of ASIC1a channels had no effect on either the basal SDH neuronal activity or the nociceptive re- sponse of normal rats. Thus, ASIC1a channels in SDH neurons are not involved in physiological nociception. This may be attributable to weak acidosis at synaptic cleft and/or low endogenous expression level of ASIC1a under normal physiological conditions. However, repetitive stimulation of the dorsal root evoked transient acidification in the dorsal horn by $0.25 \mathrm{pH}$ units (Chvatal et al., 1988). The localized changes in synaptic cleft might be more pronounced because of the limited spatial and temporal resolution of $\mathrm{pH}$ microelectrodes in the measurement (Miesenbock et al., 1998). Thus, ASICs of SDH neurons might detect acidification associated with exacerbated synaptic activity under pathological conditions, such as inflammatory chronic pain.

Although synaptic transmission is primarily mediated by AMPA subtype of glutamate receptors, intense or sustained noxious stimuli that are associated with tissue damage activate NMDA receptors, allowing $\mathrm{Ca}^{2+}$ influx into the postsynaptic cells. This influx in turn activates $\mathrm{Ca}^{2+}$-sensitive intracellular signal cascades that lead to prolonged increases in the excitability of SDH neurons, a process known as central sensitization (Woolf and Salter, 2000). However, there is growing evidence for the involvement of NMDA receptor-independent mechanisms underlying the enhanced synaptic efficacy in SDH neurons after peripheral inflammation. In particular, $\mathrm{Ca}^{2+}$-permeable AMPA receptors in SDH neurons contribute to activity-induced sensitization in pain pathways (Gu et al., 1996; Hartmann et al., 2004). The present study further demonstrates that ASIC1a channels in $\mathrm{SDH}$ neurons directly contribute to both C-fiber stimulationinduced wind-up and inflammation-induced hyperactivity of $\mathrm{SDH}$ neurons, indicating that this additional type of $\mathrm{Ca}^{2+}$ permeable channels is also important determinants of activitydependent modification of spinal processing of nociceptive signals and contribute to pain hypersensitivity. Unlike NMDA and AMPA receptors, which are involved in normal synaptic transmission, ASICla channels function specifically for spinal processing of nociceptive information during inflammatory chronic pain.

How might ASICs modulate spinal nociceptive plasticity?

The functional significance of ASICla in synaptic plasticity has been examined previously in the context of LTP and synaptic modulation associated with activity-dependent learning (Wemmie et al., 2002, 2003, 2004). Previous evidence suggests that the molecular and cellular mechanisms involved in learning and memory are also operational in nociceptive hypersensitivity and chronic pain (Sandkuhler, 2000; Ji et al., 2003; Zhuo, 2007). Interestingly, analogous to a requirement for ASIC1a in hippocampal LTP (Wemmie et al., 2002), we found that $\mathrm{Ca}^{2+}$-permeable ASIC1a channels in SDH neurons are critical for wind-up and inflammation-induced hyperactivity of SDH neurons. In addition, repetitive stimulation of the dorsal root evoked transient acidification in the dorsal horn (Chvatal et al., 1988). Thus, together with their elevated expression, ASICla channels in SDH neurons are positioned to respond to acidification associated with the persistent synaptic activity after peripheral inflammation, resulting in enhanced $\mathrm{Ca}^{2+}$ signaling and increased firing of these neurons (Vukicevic and Kellenberger, 2004). This enhanced firing may in turn facilitate the activation of NMDA receptors, leading to the activation of downstream signaling molecules, such as $\mathrm{Ca}^{2+} /$ calmodulin-stimulated adenylyl cyclases (Wei et al., 2002), mitogen-activated protein kinases (Ji et al., 1999), etc., and finally causing activity-dependent central sensitization. However, NMDA receptor activation can further sensitize the cells to acidic conditions by inducing ASIC1a phosphor- 
ylation (Gao et al., 2005). Therefore, it is likely that ASIC1a channels may function together with NMDA receptors in activitydependent central sensitization underlying pain hypersensitivity. Indeed, it has been reported that ASICla is preferentially targeted to neuronal dendrites and present in spines, where NMDA receptors are densely resident. We have not ruled out the possible role of ASIC1a modulation in inflammatory pain. However, regulation of the protein level may be more important in chronic pathological pain conditions. Even if the post-translational modulation of the ASICla channel is directly responsible for the behavioral effects, the upregulation of the ASIC1a protein will nevertheless enhance the overall effect. More importantly, previous study shows that overexpressing ASIC1a increases the number of spines (Zha et al., 2006). Thus, in the future, it would be interesting to examine whether the elevated expression of ASICla in SDH neurons after peripheral inflammation causes an altered dendritic spine density, a characteristic of several chronic brain diseases (Fiala et al., 2002).

Although ASIC1a channels appear to play a major role in central but not peripheral nociception, we should note that ASICla expression in DRG neurons is either upregulated after peripheral inflammation (Voilley et al., 2001; Mamet et al., 2002). The absence of ASICla in CGRPand $\mathrm{IB}_{4}$-containing DRG afferent terminals in the spinal cord does not necessarily imply that peripheral ASIC1a channels do not participate in pain sensation. It is possible that ASIC1a in DRG may function primarily in the peripheral terminals or in the cell body. Selective transport of ASIC2a $(\mathrm{BNaCl} \alpha)$ toward DRG peripheral terminals was indeed observed (Garcia-Anoveros et al., 2001). Nevertheless, most previous studies on ASICs and pain regulation have so far focused on changes in subunit expression in DRG neurons (Garcia-Anoveros et al., 2001; Voilley et al., 2001; Chen et al., 2002; Mamet et al., 2002; Poirot et al., 2006). Our study indicates that inflammatory pain may result from changes in ASIC subunit expression in both DRG and higher-order spinal cord neurons. Supraspinal structures such as thalamus and cortex are also known to be involved in the chronic pain (Wu et al., 2005; Zhuo, 2007). It has been reported that ASICs are functionally expressed in hippocampus (Wemmie et al., 2002), amygdala, and cortex (Wemmie et al., 2003, 2004). However, it is still unknown whether suprospinal ASICs are engaged in the modulation of chronic pain hypersensitivity. Although we demonstrate that ASICla channels in SDH neurons contribute to inflammatory pain hypersensitivity, we cannot rule out the involvement of ASICla in neuropathic pain $50 \mu \mathrm{m}$.
B

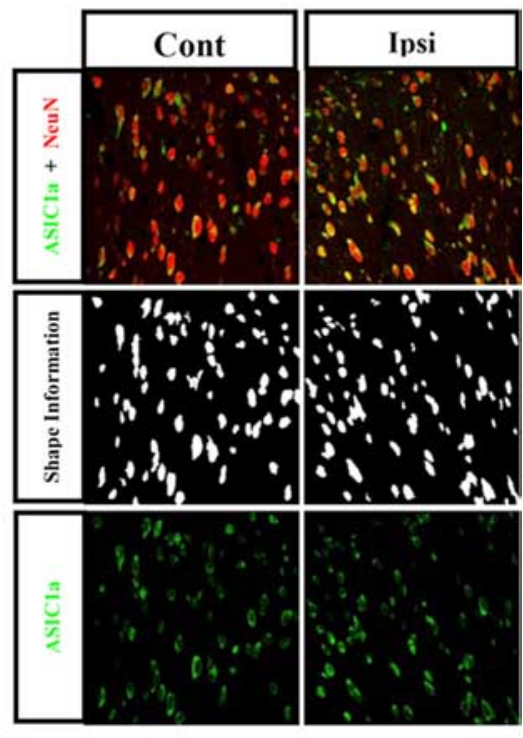

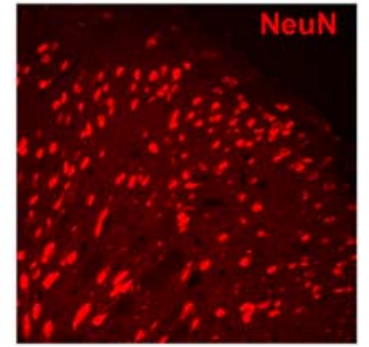

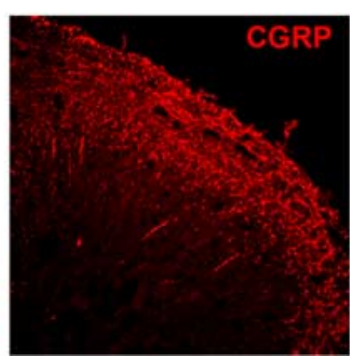

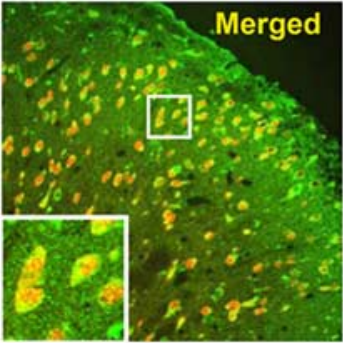

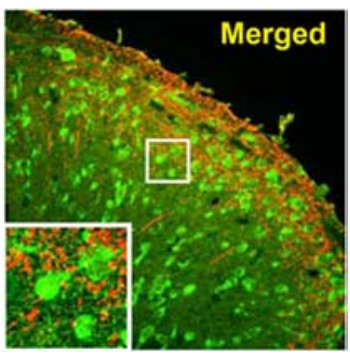

Figure 6. Increased ASIC1a expression in SDH neurons after peripheral inflammation. $A$, ASIC1a immunostaining in SDH contralateral (Cont) and ipsilateral (Ipsi) to the injection site $1 \mathrm{~d}$ after CFA injection, with the staining intensity coded by pseudocolors. $\boldsymbol{B}$, Illustration of the calculation of ASIC1a intensity in NeuN-positive SDH neurons (marked region in $\boldsymbol{A}$ ). Shape information was extracted from NeuN staining. C, Average staining intensity of ASIC1a in SDH neurons, for ipsilateral and contralateral sides, normalized by the mean level from saline-injected rats (Sham). Data are shown as mean \pm SE (Sham, $n=1178 ;$ Ipsi, $n=968$; Cont, $n=963$. Immunostainings were performed from nine sections of three sham or inflamed rats, respectively. ${ }^{* * *} p \leq 0.001$ (Student's unpaired $t$ test). D, Coimmunostaining of ASIC1a with NeuN (a neuron-specific marker) or CGRP (a marker of primary afferents) in superficial layers of SDH. Insets, High magnification view of the area marked by the square. Scale bars: $A, 200 \mu \mathrm{m} ; \boldsymbol{D}$,

models. In fact, previous evidence suggests a role of ASIC1a channels in neuropathic pain (Poirot et al., 2006; Mazzuca et al., 2007).

In summary, the present results suggest that enhanced $\mathrm{Ca}^{2+}$ signaling in spinal dorsal horn neurons after peripheral inflammation, through the upregulation of ASIC1a channels, may contribute to hypersensitivity of SDH neurons and inflammatory pain. Thus, specific blockade of $\mathrm{Ca}^{2+}$-permeable ASIC1a channels may have antinociceptive effect by reducing or preventingthe development of spinal sensitization induced by inflammation. 
A

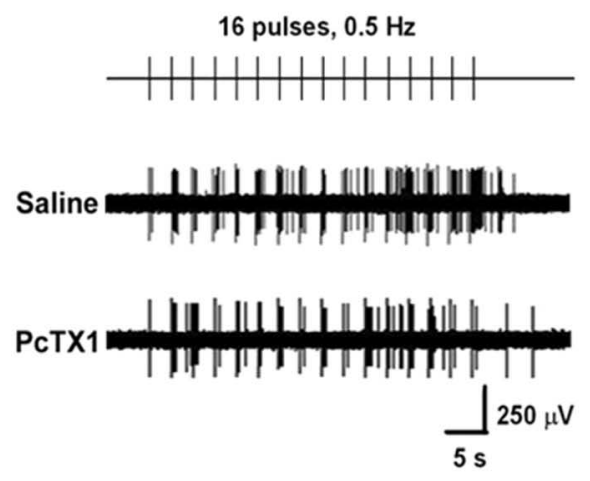

B

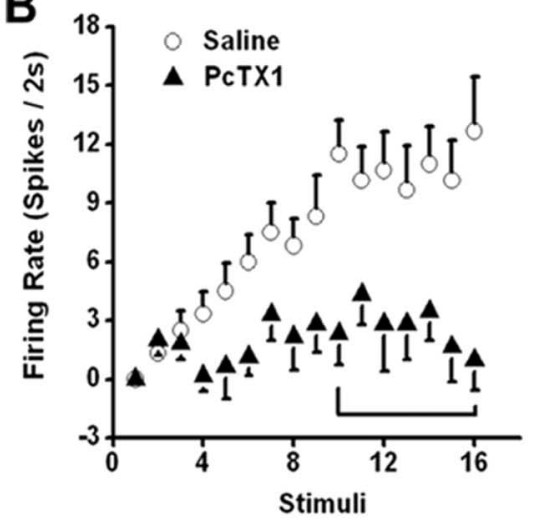

C

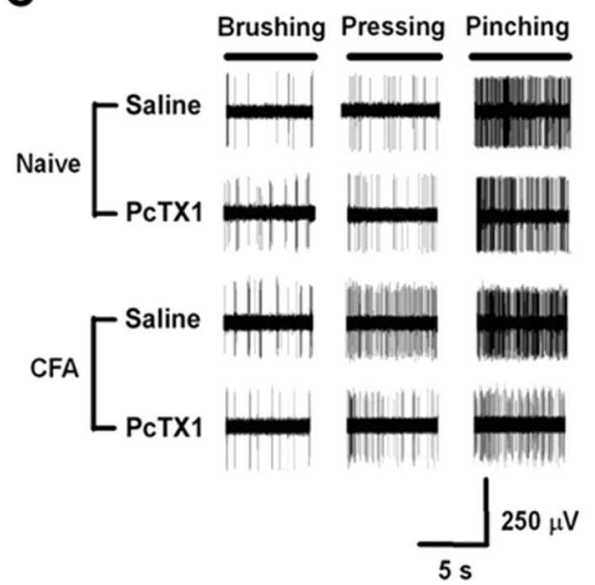

D

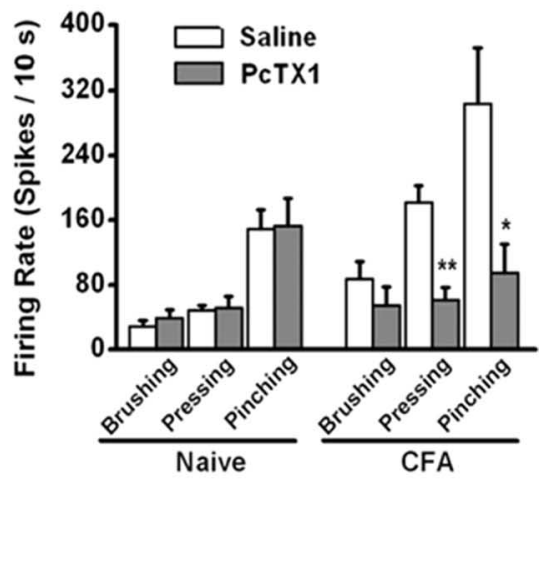

Figure 7. Blocking ASIC1a channels attenuated C-fiber-induced wind-up and CFA-induced hypersensitivity of SDH nociceptive neurons. $\boldsymbol{A}$, An example of wind-up in spinal WDR neurons after repetitive C-fiber stimulation (16 suprathreshold stimuli, $2 \mathrm{~ms}$ pulse width at $0.5 \mathrm{~Hz}$ ) in normal rats. The wind-up was mostly abolished after infusion of PcTX1, but not saline, into the dorsal surface of spinal cord. The downward arrows in $\boldsymbol{A}$ indicate the starting time of electrical stimulation. $\boldsymbol{B}$, Summary of results from all experiments similar to that shown in $A$. Data are shown as mean $\pm \mathrm{SE}(n=6$ for each group). The bracket indicates significant difference from corresponding points in the saline group ( $p<0.05$, Student's unpaired $t$ test). C, Example recordings showing the effect of PcTX1 on the firing of WDR neurons in response to non-noxious (brushing) or noxious (pressing and pinching) mechanical stimulation applied to their cutaneous receptive fields in naive $(n=5)$ and CFA-treated rats $(n=4)$. D, Summary of results from all experiments similar to that in $C$. Data are shown as mean \pm SE $(n=4-5)$. The CFA treatment significantly increased the firing rate for all stimuli $(p<0.05)$ and PCTX1 significantly reduced the CFA effect $\left({ }^{*} p<0.05 ;{ }^{* *} p \leq 0.01\right.$ compared with saline groups, Student's unpaired $t$ test).

Through membrane depolarization, activation of ASICla channels may also indirectly exerts its effect via relief of $\mathrm{Mg}^{2+}$ blockade of NMDA receptors, which are essential for spinal nociceptive plasticity underlying chronic pain. Because blockers of NMDA receptors used for treatment of chronic pain have severe side effects (South et al., 2003), specific disruption of $\mathrm{Ca}^{2+}$ permeable ASICla channels might offer an alternative therapeutic approach.

\section{References}

Bandell M, Story GM, Hwang SW, Viswanath V, Eid SR, Petrus MJ, Earley TJ, Patapoutian A (2004) Noxious cold ion channel TRPA1 is activated by pungent compounds and bradykinin. Neuron 41:849-857.

Basbaum AI, Woolf CJ (1999) Pain. Curr Biol 9:R429-R431.

Caterina MJ, Leffler A, Malmberg AB, Martin WJ, Trafton J, Petersen-Zeitz KR, Koltzenburg M, Basbaum AI, Julius D (2000) Impaired nociception and pain sensation in mice lacking the capsaicin receptor. Science 288:306-313.

Chaplan SR, Bach FW, Pogrel JW, Chung JM, Yaksh TL (1994) Quantitative assessment of tactile allodynia in the rat paw. J Neurosci Methods 53:55-63.
Chen CC, Zimmer A, Sun WH, Hall J, Brownstein MJ, Zimmer A (2002) A role for ASIC3 in the modulation of high-intensity pain stimuli. Proc Natl Acad Sci USA 99:8992-8997.

Chen J, Luo C, Li HL (1998) The contribution of spinal neuronal changes to development of prolonged, tonic nociceptive responses of the cat induced by subcutaneous bee venom injection. Eur J Pain 2:359-376.

Chen X, Kalbacher H, Grunder S (2006) Interaction of acid-sensing ion channel (ASIC) 1 with the tarantula toxin psalmotoxin 1 is state dependent. J Gen Physiol 127:267-276.

Chvatal A, Jendelova P, Kriz N, Sykova E (1988) Stimulation-evoked changes in extracellular $\mathrm{pH}$, calcium and potassium activity in the frog spinal cord. Physiol Bohemoslov 37:203-212.

Dickenson AH, Sullivan AF (1987) Subcutaneous formalin-induced activity of dorsal horn neurones in the rat: differential response to an intrathecal opiate administered pre or post formalin. Pain 30:349-360.

Dube GR, Lehto SG, Breese NM, Baker SJ, Wang $\mathrm{X}$, Matulenko MA, Honore P, Stewart AO, Moreland RB, Brioni JD (2005) Electrophysiological and in vivo characterization of A-317567, a novel blocker of acid sensing ion channels. Pain 117:88-96.

Dubner R, Ruda MA (1992) Activity-dependent neuronal plasticity following tissue injury and inflammation. Trends Neurosci 15:96-103.

Escoubas P, De Weille JR, Lecoq A, Diochot S, Waldmann R, Champigny G, Moinier D, Menez A, Lazdunski M (2000) Isolation of a tarantula toxin specific for a class of protongated $\mathrm{Na}^{+}$channels. J Biol Chem 275:25116-25121.

Ettaiche M, Deval E, Cougnon M, Lazdunski M, Voilley N (2006) Silencing acid-sensing ion channel la alters cone-mediated retinal function. J Neurosci 26:5800-5809.

Fiala JC, Spacek J, Harris KM (2002) Dendritic spine pathology: cause or consequence of neurological disorders? Brain Res Brain Res Rev 39:29-54.

Gao J, Duan B, Wang DG, Deng XH, Zhang GY, $\mathrm{Xu}$ L, Xu TL (2005) Coupling between NMDA receptor and acid-sensing ion channel contributes to ischemic neuronal death. Neuron 48:635-646.

Garcia-Anoveros J, Samad TA, Zuvela-Jelaska L, Woolf CJ, Corey DP (2001) Transport and localization of the DEG/ $\mathrm{ENaC}$ ion channel $\mathrm{BNaC} 1 \alpha$ to peripheral mechanosensory terminals of dorsal root ganglia neurons. J Neurosci 21:2678-2686.

Gu JG, Albuquerque C, Lee CJ, MacDermott AB (1996) Synaptic strengthening through activation of $\mathrm{Ca}^{2+}$-permeable AMPA receptors. Nature 381:793-796.

Hartmann B, Ahmadi S, Heppenstall PA, Lewin GR, Schott C, Borchardt T, Seeburg PH, Zeilhofer HU, Sprengel R, Kuner R (2004) The AMPA receptor subunits GluR-A and GluR-B reciprocally modulate spinal synaptic plasticity and inflammatory pain. Neuron 44:637-650.

Herrero JF, Laird JM, Lopez-Garcia JA (2000) Wind-up of spinal cord neurones and pain sensation: much ado about something? Prog Neurobiol 61:169-203.

Hokfelt T, Arvidsson U, Ceccatelli S, Cortes R, Cullheim S, Dagerlind A, Johnson H, Orazzo C, Piehl F, Pieribone V, Schalling M, Terenius L, Ulfhake B, Verge VM, Villar M, Wiesenfeldhallin Z, Xu XJ, Xu Z (1992) Calcitonin gene-related peptide in the brain, spinal cord, and some peripheral systems. Ann NY Acad Sci 657:119-134.

Hu HJ, Carrasquillo Y, Karim F, Jung WE, Nerbonne JM, Schwarz TL, Gereau IV RW (2006) The kv4.2 potassium channel subunit is required for pain plasticity. Neuron 50:89-100. 
Ikeda H, Stark J, Fischer H, Wagner M, Drdla R, Jager T, Sandkuhler J (2006) Synaptic amplifier of inflammatory pain in the spinal dorsal horn. Science 312:1659-1662.

Ji RR, Baba H, Brenner GJ, Woolf CJ (1999) Nociceptive-specific activation of ERK in spinal neurons contributes to pain hypersensitivity. Nat Neurosci 2:1114-1119.

Ji RR, Kohno T, Moore KA, Woolf CJ (2003) Central sensitization and LTP: do pain and memory share similar mechanisms? Trends Neurosci 26:696-705.

Jiang MC, Cleland CL, Gebhart GF (1995) Intrinsic properties of deep dorsal horn neurons in the L6-S1 spinal cord of the intact rat. J Neurophysiol 74:1819-1827.

Jiang P, Yang CX, Wang YT, Xu TL (2006) Mechanisms of modulation of pregnanolone on glycinergic response in cultured spinal dorsal horn neurons of rat. Neuroscience 141:2041-2050.

Jones NG, Slater R, Cadiou H, McNaughton P, McMahon SB (2004) Acidinduced pain and its modulation in humans. J Neurosci 24:10974-10979.

Krishtal O (2003) The ASICs: signaling molecules? Modulators? Trends Neurosci 26:477-483.

Mamet J, Baron A, Lazdunski M, Voilley N (2002) Proinflammatory mediators, stimulators of sensory neuron excitability via the expression of acid-sensing ion channels. J Neurosci 22:10662-10670.

Mazzuca M, Heurteaux C, Alloui A, Diochot S, Baron A, Voilley N, Blondeau N, Escoubas P, Gelot A, Cupo A, Zimmer A, Zimmer AM, Eschalier A, Lazdunski M (2007) A tarantula peptide against pain via ASIC1a channels and opioid mechanisms. Nat Neurosci 10:943-945.

Miesenbock G, De Angelis DA, Rothman JE (1998) Visualizing secretion and synaptic transmission with $\mathrm{pH}$-sensitive green fluorescent proteins. Nature 394:192-195.

Mogil JS, Breese NM, Witty MF, Ritchie J, Rainville ML, Ase A, Abbadi N, Stucky CL, Seguela P (2005) Transgenic expression of a dominantnegative ASIC3 subunit leads to increased sensitivity to mechanical and inflammatory stimuli. J Neurosci 25:9893-9901.

Mullen RJ, Buck CR, Smith AM (1992) NeuN, a neuronal specific nuclear protein in vertebrates. Development 116:201-211.

Poirot O, Berta T, Decosterd I, Kellenberger S (2006) Distinct ASIC currents are expressed in rat putative nociceptors and are modulated by nerve injury. J Physiol (Lond) 576:215-234.

Salter MW (2004) Cellular neuroplasticity mechanisms mediating pain persistence. J Orofac Pain 18:318-324.

Salter MW (2005) Cellular signalling pathways of spinal pain neuroplasticity as targets for analgesic development. Curr Top Med Chem 5:557-567.

Sandkuhler J (2000) Learning and memory in pain pathways. Pain 88:113-118.

Silverman JD, Kruger L (1990) Selective neuronal glycoconjugate expression in sensory and autonomic ganglia: relation of lectin reactivity to peptide and enzyme markers. J Neurocytol 19:789-801.

Sluka KA, Price MP, Breese NM, Stucky CL, Wemmie JA, Welsh MJ (2003) Chronic hyperalgesia induced by repeated acid injections in muscle is abolished by the loss of ASIC3, but not ASIC1. Pain 106:229-239.

South SM, Kohno T, Kaspar BK, Hegarty D, Vissel B, Drake CT, Ohata M, Jenab S, Sailer AW, Malkmus S, Masuyama T, Horner P, Bogulavsky J, Gage FH, Yaksh TL, Woolf CJ, Heinemann SF, Inturrisi CE (2003) A conditional deletion of the NR1 subunit of the NMDA receptor in adult spinal cord dorsal horn reduces NMDA currents and injury-induced pain. J Neurosci 23:5031-5040.

Stein C, Millan MJ, Herz A (1988) Unilateral inflammation of the hindpaw in rats as a model of prolonged noxious stimulation: alterations in behavior and nociceptive thresholds. Pharmacol Biochem Behav 31:451-455.

Ugawa S, Ueda T, Ishida Y, Nishigaki M, Shibata Y, Shimada S (2002)
Amiloride-blockable acid-sensing ion channels are leading acid sensors expressed in human nociceptors. J Clin Invest 110:1185-1190.

Voilley N, de Weille J, Mamet J, Lazdunski M (2001) Nonsteroid antiinflammatory drugs inhibit both the activity and the inflammationinduced expression of acid-sensing ion channels in nociceptors. J Neurosci 21:8026-8033.

Vukicevic M, Kellenberger S (2004) Modulatory effects of acid-sensing ion channels on action potential generation in hippocampal neurons. Am J Physiol Cell Physiol 287:C682-C690.

Wang W, Duan B, Xu H, Xu L, Xu TL (2006) Calcium-permeable acidsensing ion channel is a molecular target of the neurotoxic metal ion lead. J Biol Chem 281:2497-2505.

Wei F, Qiu CS, Kim SJ, Muglia L, Maas JW, Pineda VV, Xu HM, Chen ZF, Storm DR, Muglia LJ, Zhuo M (2002) Genetic elimination of behavioral sensitization in mice lacking calmodulin-stimulated adenylyl cyclases. Neuron 36:713-726.

Wei F, Vadakkan KI, Toyoda H, Wu LJ, Zhao MG, Xu H, Shum FW, Jia YH, Zhuo M (2006) Calcium calmodulin-stimulated adenylyl cyclases contribute to activation of extracellular signal-regulated kinase in spinal dorsal horn neurons in adult rats and mice. J Neurosci 26:851-861.

Wemmie JA, Chen J, Askwith CC, Hruska-Hageman AM, Price MP, Nolan BC, Yoder PG, Lamani E, Hoshi T, Freeman Jr JH, Welsh MJ (2002) The acid-activated ion channel ASIC contributes to synaptic plasticity, learning, and memory. Neuron 34:463-477.

Wemmie JA, Askwith CC, Lamani E, Cassell MD, Freeman Jr JH, Welsh MJ (2003) Acid-sensing ion channel 1 is localized in brain regions with high synaptic density and contributes to fear conditioning. J Neurosci 23:5496-5502.

Wemmie JA, Coryell MW, Askwith CC, Lamani E, Leonard AS, Sigmund CD, Welsh MJ (2004) Overexpression of acid-sensing ion channel 1a in transgenic mice increases acquired fear-related behavior. Proc Natl Acad Sci USA 101:3621-3626.

Wemmie JA, Price MP, Welsh MJ (2006) Acid-sensing ion channels: advances, questions and therapeutic opportunities. Trends Neurosci 29:578-586.

Woolf CJ, Costigan M (1999) Transcriptional and posttranslational plasticity and the generation of inflammatory pain. Proc Natl Acad Sci USA 96:7723-7730.

Woolf CJ, Salter MW (2000) Neuronal plasticity: increasing the gain in pain. Science 288:1765-1769.

Wu LJ, Duan B, Mei YD, Gao J, Chen JG, Zhuo M, Xu L, Wu M, Xu TL (2004) Characterization of acid-sensing ion channels in dorsal horn neurons of rat spinal cord. J Biol Chem 279:43716-43724.

Wu LJ, Toyoda H, Zhao MG, Lee YS, Tang J, Ko SW, Jia YH, Shum FW, Zerbinatti CV, Bu G, Wei F, Xu TL, Muglia LJ, Chen ZF, Auberson YP, Kaang BK, Zhuo M (2005) Upregulation of forebrain NMDA NR2B receptors contributes to behavioral sensitization after inflammation. J Neurosci 25:11107-11116.

Xiong ZG, Zhu XM, Chu XP, Minami M, Hey J, Wei WL, MacDonald JF, Wemmie JA, Price MP, Welsh MJ, Simon RP (2004) Neuroprotection in ischemia: blocking calcium-permeable acid-sensing ion channels. Cell 118:687-698.

Yermolaieva O, Leonard AS, Schnizler MK, Abboud FM, Welsh MJ (2004) Extracellular acidosis increases neuronal cell calcium by activating acidsensing ion channel 1a. Proc Natl Acad Sci USA 101:6752-6757.

Zha XM, Wemmie JA, Green SH, Welsh MJ (2006) Acid-sensing ion channel $1 \mathrm{a}$ is a postsynaptic proton receptor that affects the density of dendritic spines. Proc Natl Acad Sci USA 103:16556-16561.

Zhuo M (2007) Neuronal mechanism for neuropathic pain. Mol Pain 3-14: $1-9$. 